\title{
Inadequate Knowledge About Sexually Transmitted Diseases[STDS] And Risky Sexual Behaviour: The Risk Factors for Wild Spread Of STDS Among Youth in Developing Countries \\ Oluwafemi Olawuyi*
}

\author{
Address: University College Hospital, Oyo State, Nigeria \\ Email: Oluwafemi Olawuyi* - drgrsb@yahoo.com \\ * Corresponding author ‡Presenting author
}

\author{
from 2005 International Meeting of The Institute of Human Virology \\ Baltimore, USA, 29 August - 2 September 2005 \\ Published: 8 December 2005 \\ Retrovirology 2005, 2(SuppI I):P74 doi:I0.I I86/1742-4690-2-SI-P74
}

\section{Issues}

This abstract shows that the low level of knowledge and risky sexual behaviour of youth are the risk factors for the high rate of spread of STDs among Nigerian youth.

\section{Description}

A self developed validated and reliable questionnaire $[\mathrm{r}=$ 0.77] was used to collect the data needed for the study and percentage was used to analyze the data. The population of the study was made up of the resident undergraduate/ graduate students in male hostels in the Obafemi Awolowo University, Ile-Ife, Osun state, Nigeria. The sample size is 636 selected through simple random sampling technique. The demographic data is as followings: Out of 636 respondents, 11 were below 16 years old, 95 were between 16 and 20, 309 were between 21 and 25, and 223, between 26 years and above. Two well developed tables were constructed. Relative Risk [RR] calculated is 1.7 , i.e. $\mathrm{RR}>1$, indicating that the factors are risk factors, and the Confidential Interval [CI] for RR at 95\% Significant level is $1.61<1.7<1.79$ from the formula, CI Lower limit $<$ RR $<$ CI Upper limit.

\section{Lessons Learned}

In table 1 which shows the knowledge of the respondents about STDs, revealed that $36.65 \%$ responses had knowledge about the diseases. Table 2 which shows the risky sexual behaviour of the respondents, revealed that the higher education students in Nigeria do engage in one risky sexual behaviour or the other, with majority of them having multiple sexual partners without using condom during the sexual intercourse, and this makes them highly prone to STDs including HIV/AIDS.

\section{Conclusion and Recommendations}

It is clearly seen that low level of knowledge and engagement in risky sexual behaviour are the obvious risk factors for the high rate of STDs in Nigerian youth and most developing countries. 